\title{
Oxidative stress in equine medicine - Current knowledge
}

\author{
Nathalie Kirschvink and P. Lekeux \\ Department for Functional Sciences, Faculty of Veterinary Medicine, University of Liege
}

\begin{abstract}
Summary
Oxidative stress has become of increasing interest in research and human medicine. Oxidants or reactive oxygen species are generated by metabolic reactions and play an important role for the immune defence and the "redox-regulation" of gene expression. In physiological conditions, different categories of antioxidants maintain the equilibrium between the pro-oxidant burden and the endogenous antioxidant defence. However, when an imbalance between oxidants and antioxidants in favour of oxidants occurs, oxidative stress might induce irreversible lesions that can be evidenced and characterised by oxidant markers. In equine medicine, it has been shown that oxidative stress is occurring in lower airway disease and equine motor neuron disease. Moreover, adapted antioxidants therapy appears to have a beneficial effect on the antioxidant-oxidant imbalance. Exercise-induced oxidative stress and its impact on animal welfare and performance are also under investigation in equine sports medicine. Oxidative stress has been demonstrated to depend on exercise type, intensity and duration. It might be modulated by training and/or adapted antioxidant therapy, aiming to maintain the antioxidant-oxidant equilibrium and thereby to improve animal welfare.
\end{abstract}

Keywords: oxidative stress, oxidant markers, airway disease, EMND; equine motor neuron disease, exercise, antioxidants

\section{Oxidativer Stress beim Pferd - aktueller Wissensstand}

Der oxidative Stress hat in der Humanmedizin zunehmend an Forschungsinteresse gewonnen. Oxydierend wirkende Moleküle oder sogenannte "reactive oxygen species" werden bei Stoffwechselprozessen produziert und sie spielen für das Immunsystem und in der sogenannten "Redox-Regulation" der genetischen Expression eine wichtige Rolle. Unter physiologischen Bedingungen erhalten Antioxydantien das Gleichgewicht zwischen der pro-oxydativen Belastung und den endogenen Antioxydantien. Wird dieses Gleichgewicht zugunsten von ProOxydantien gestört, entsteht oxidativer Stress, dessen irreversible Schädigung anhand von Markern festgestellt und charakterisiert werden kann. In der Tiermedizin ist beim Pferd erwiesen, dass oxidativer Stress bei Atemwegserkrankungen sowie bei der "equine motor neuron disease" entsteht. Darüber hinaus scheint eine entsprechende Behandlung mit Antioxydantien einen positiven Effekt auf das Gleichgewicht zwischen Oxydantien und Antioxydantien zu haben. Belastungsinduzierter oxidativer Stress und dessen Einfluss auf Wohlbefinden und Leistung werden ebenfalls in der Sportmedizin beim Pferd untersucht. In diesem Fall hängt der entstehende oxidative Stress von Art, Intensität und Daver der Belastung ab. Training und/oder angepasste Antioxydantien können das Gleichgewicht zwischen Antioxydantien und Oxydantien verbessern und somit zur Gesundheit des Tieres beitragen.

Schlüsselwörter: Oxidativer Stress, Atemwegserkrankung, EMND, equine motor neuron disease, Belastung, Antioxydantien

\section{Introduction}

Oxidants: origin and physiological roles

Since Davies et al. have demonstrated in 1982 that physical exercise is generating free radicals, their role and effects on the organism have become of increasing interest. Free radicals are molecules that have an unpaired electron in their outer orbit, which increases their reactivity with other molecules. Reactive oxidant species (ROS) can be defined as oxygencontaining molecules that are more reactive than the triplet oxygen molecule present in air (Noguchi and Niki, 1999). At present, ROS are considered to be important messengers acting in living organisms, which are constantly produced by numerous metabolic reactions. The generation of ROS is increased by phagocytes during inflammatory processes as well as by physical exercise via the upregulation of the mitochondrial metabolism. Some enzymes, such as oxidases, are also able to generate ROS (Cheeseman and Slater, 1993; Ji, 1995).

The most important role of ROS is the defence against invading microorganisms and the so-called "redox-regulation" of gene expression (MacPherson et al., 2001 ; Stamler \& Meis- ner, 2001). The generation of ROS is significantly increased in inflammatory conditions during the "oxidative burst" of neutrophils and macrophages (Rahman et al., 1996). The activation of pro-oxidative enzymes, such as the NADPH-oxidase (nicotinamide adenine dinucleotide phosphate oxidase) and the myeloperoxidase (MPO) in presence of transition metals such as copper or iron, allows the generation of important amounts of ROS that are released by inflammatory cells. These oxidants play an important role in the inactivation and destruction of microorganisms by inducing peroxidation and destabilization of their lipid membranes, oxidation and inactivation of their proteins acting as receptors or enzymes and oxidation of their nuclear material (Kowaltowski and Vercesi, 1999; Kobayashi et al., 2001). Beside this important role for immunity, the ROS are also cellular messengers. The redox-regulation of intracellular signal transduction is based on the oxidation and reduction of messenger proteins, thereby activating or inactivating intracellular pathways. Especially the expression of inflammatory genes is depending on oxidation-reduction reactions, which confers to the ROS the role of pro-inflammatory stimuli (Hensley et al., 2000). 
Antioxidants: origins and physiological roles

The antioxidant defence against ROS implies (1) systems that prevent ROS generation, (2) systems that inactivates ROS and (3) systems able to limit the deleterious effects of ROS (Cheeseman and Slater, 1993).

The prevention of ROS generation occurs mainly within the mitochondrial respiratory chain where enzymatic complexes prevent electron leakage. Furthermore, proteins binding free iron and copper, such as transferrin, ferritin, ceruloplasmin or albumin, further decrease the cellular capacity of ROS generation (Beckmann and Ames, 1998).

The major part of antioxidants is implied in the inactivation or transformation of ROS. Oxidants can either be transformed by antioxidant enzymes into less reactive forms or can react with antioxidant molecules that are chemically stable. The

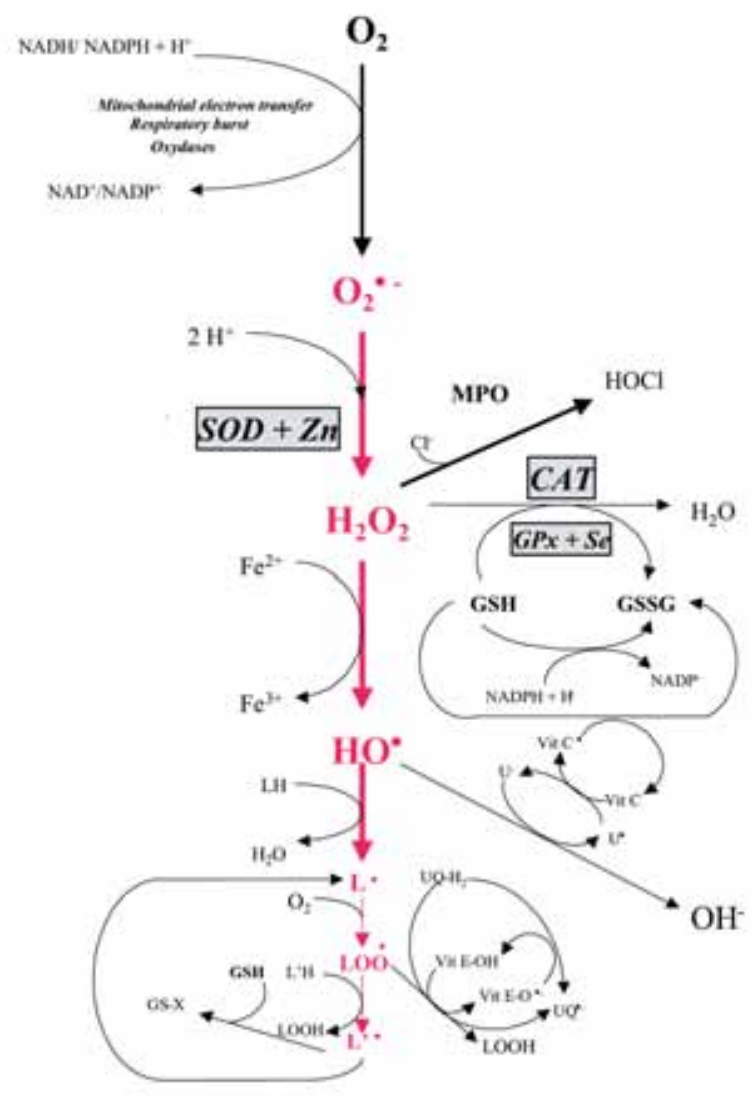

Fig 1 Principal oxidative pathways occurring in living organisms and main antioxidant systems transforming or inactivating free radicals or reactive oxidant species. $\mathrm{O}_{2}$ : oxygen, $\mathrm{O}_{2}$-: superoxide anion, $\mathrm{H}_{2} \mathrm{O}_{2}$ : hydrogen peroxide, $\mathrm{HO}$ : hydroxyl radical, LH: fatty acid, L.: fatty acid radical, LOO: lipid peroxide, SOD: superoxide dismutase, CAT: catalase, GPx: glutathione peroxidase, MPO: myeloperoxidase, GSH: reduced glutathione, GSSG: oxidised glutathione, NADPH: nicotinamide adenine phosphate, $U$ : uric acid, Vit $C$ : vitamine $C$, Vit $E$ : vitamine $E, U Q$ : ubiquinone.

Darstellung der wichtigsten oxidativen Reaktionen sowie der verschiedenen Antioxydantien die freie Radikale oder "reactive oxygen species" transformieren oder inaktivieren. $\mathrm{O}_{2}$ : Saverstoff, $\mathrm{O}_{2}$ : Superoxyd-Anion, $\mathrm{H}_{2} \mathrm{O}_{2}$ : Wasserstoffperoxyd, $\mathrm{HO}$.: Hydroxylradikal, LH: Fettsäure, L.: Fettsäureradikal, LOO: Fettsäureperoxyd, SOD: Superoxyd-Dismutase, CAT: Catalase, GPx: Glutathionperoxydase, MPO: Myeloperoxydase, GSH: reduziertes Glutathion, GSSG: oxydiertes Glutathion, NADPH: Nicotinamid Adenin Phosphat, U: Harnsäure, Vit C: Vitamin C, Vit E: Vitamin E, UQ: Ubiquinon. most important antioxidant enzymes are superoxide dismutase (SOD), catalase (CAT) and glutathioneperoxidase (GPx) (Fridovich, 1995). The catalytic activity of these enzymes allows the transformation of superoxide anion into hydrogen peroxide and water, thereby inactivating important amounts of ROS (Fig. 1). Oligo-elements, such as selenium (Se) and zinc $(Z n)$, play an important catalytic role for the enzymatic activity of GPx and SOD, respectively (Maughan, 1999; Matès, 2000).

However, small antioxidant molecules are the most numerous endogenous antioxidants (see for review Cheeseman and Slater, 1993). They can be divided into two groups: hydrophobic and hydrophilic antioxidants. The former are mainly composed by a-tocopherol (vitamin E), b-carotene (vitamin A), flavonoids, ubiquinol, bilirubine and melatonin and are essentially protecting lipids from chain reactions of peroxidation. On the other hand, the hydrophilic antioxidants such as glutathione (existing under its reduced [GSH] and oxidized form [GSSG]), uric acid, ascorbic acid (vitamin C), thiols, proteoglycans and hyaluronic acid protect from lipid peroxidation as well as from protein, carbohydrate and nuclear material oxidation. Figure 1 displays the major oxidant pathways as well the role of the most important antioxidants and their interactions.

If oxidation of cellular components has not been prevented by antioxidants, several mechanisms inducing lyses or reparation of oxidized proteins, lipids or nuclear material can be activated, thereby limiting functional repercussions of oxidative damage (Winrow et al., 1993; Beckman and Ames, 1998).

Oxidative stress: an imbalance between oxidants and antioxidants

As long as the oxidant burden can be counterbalanced by the antioxidant defence systems, ROS play a physiological role for the organism. However, if the equilibrium between oxidants and antioxidants is disturbed in favour of oxidants, irreversible cellular damage and/or persistent activation of pathological pathways may occur. This imbalance has been defined by Sies as an "oxidative stress" (1991) (Fig 2). In

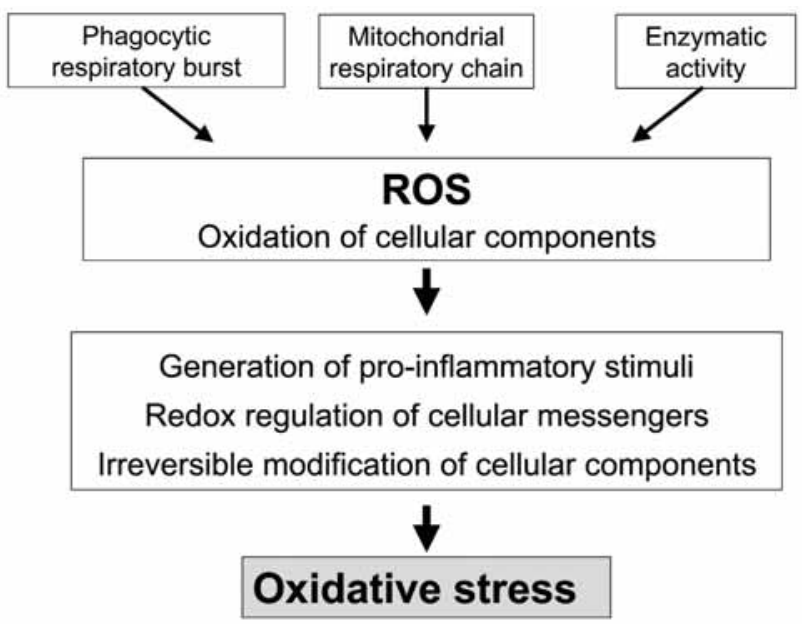

Fig 2 Principal sources or reactive oxygen species (ROS) and cellular modifications leading to oxidative stress.

Darstellung der wichtigsten Ursachen der Produktion von Oxydantien sowie der zellulären Veränderungen, die zum oxidativen Stress führen. 
human medicine, oxidative stress has been evidenced in numerous pathological conditions, such as chronic airway disease, cardio-vascular disease, degenerative neurological disorders, etc. (for review see Babior, 2000; Cuzzocrea et al., 2001). At present, oxidative processes appear to be more than a consequence of inflammatory or degenerative processes; in certain conditions, they are considered to be active pathogenic players and potential therapeutical targets (Young and Woodside, 2001).

\section{Diagnosis of oxidative stress: oxidant markers}

Oxidative stress can either be evidenced by the presence of free radicals or by their "fingerprints", which are oxidant markers (for review see de Zwart et al., 1999). Free radical detection allows the identification and localization of ROS, but necessitates very complex equipment that is rarely available. The use of oxidant markers is therefore widely practised, as well as in research and as in human medicine. Two categories of oxidant markers exist: (1) antioxidants, which comprise enzymes (SOD, CAT, GPx), hydrophobic and hydrophilic antioxidant molecules (see here above) and (2) oxidative products, such as lipids, proteins or nuclear material that has been oxidized by ROS (Pincemail et al., 1997).

Lipids are predominantly peroxidized by ROS and numerous lipid markers are described, such as isoprostanes, oxidized lipoproteins, hydroperoxides, "thiobarbituric reacting substances (TBARS) (Favier, 1995; de Zwart et al., 1999). Especially proteins, which belong to the group of thiols $(-\mathrm{SH})$, undergo oxidation that can be detected by different analytic techniques (Hawkins and Davies, 2001). The investigation of markers of oxidized nuclear material is gaining attention for research in mutagenesis and aging (Tremblay et al. 1999; Kostoryz and Yourtee, 2001).

A last manner to evidence oxidative stress is either to detect specifically activated enzymes, such as myeloperoxidase (MPO) or xanthine-oxidase (XO) (Nivière and Fontecave, 1995) or to determine increased concentrations of metals that catalyse oxidative reactions, such as free iron and copper (Reilly and Aust, 1999). The main methods to evidence oxidative stress are shown in Figure 3.

\section{Oxidative stress in equine medicine}

Since several years, oxidative stress has also been investigated in equine medicine and first evidences that an imbalance between antioxidants and oxidants in favour of oxidants might play a deleterious role for the equine organism are available. The present review aims to summarize present knowledge on disease- and exercise-related oxidative stress in equine medicine.

\section{Disease-related oxidative stress}

\section{Oxidative stress in airway disease}

The first report about oxidative processes in inflamed airways has been published by Mills et al. in young racehorses (1996b). In this study, the bronchoscopic inflammatory score of lower airways was positively correlated with the glutathione redox ratio $(G R R=(G S S G /[G S S G+G S H])$ of the bron- choalveolar lavage fluid (BALF), which is reflecting the degree of oxidation of the antioxidant glutathione (GSH = reduced form; GSSG = oxidized form). This correlation between the severity of airway inflammation and the oxidation of GSH was a first indication that inflamed equine airways undergo oxidative stress.

Art et al. (1999) compared the BALF concentration of GSH and GSSG between healthy and heaves-affected horses and reported an increase of BALF GSH and GRR in the former, suggesting an increased antioxidant defence but also a higher degree of oxidation in horses suffering from chronic lower airway inflammation. In another study investigating healthy and heaves-affected horses in clinical remission or in clinical crisis, a significant positive correlation between BALF uric acid, GRR, isoprostane (8-iso-PGF2a) and percentage of BALF polymorphonuclear neutrophils was observed (Kirschvink et al., 2002a). Furthermore, BALF GRR and isoprostane concentrations were significantly correlated with lung dysfunction (total lung resistance, dynamic lung compliance, arterial oxygen tension). Interestingly, also blood GSH concentrations were significantly increased in heaves-affected horses, the horses in remission showing intermediate values between healthy horses and heaves-affected horses in crisis. These results indicate that airway inflammation was inducing a pulmonary oxidative stress that was depending on severity of the inflammatory process and that had repercussions of the systemic (circulatory) oxidant status. In a further study, the effect of a natural antioxidant "cocktail" (versus placebo-treatment) on airway inflammation and oxidant status in blood and BALF was tested in heaves-affected horses that were in clinical remission (Kirschvink et al., 2002b). It was shown that the airway inflammation quantified by scoring bronchoscopic records was reduced after the antioxidant treatment and that there was a tendency of the blood antioxidant status to be improved.

Oxidative stress is also believed to play an eventual role in the pathogenesis of exercise-induced pulmonary haemorrhage

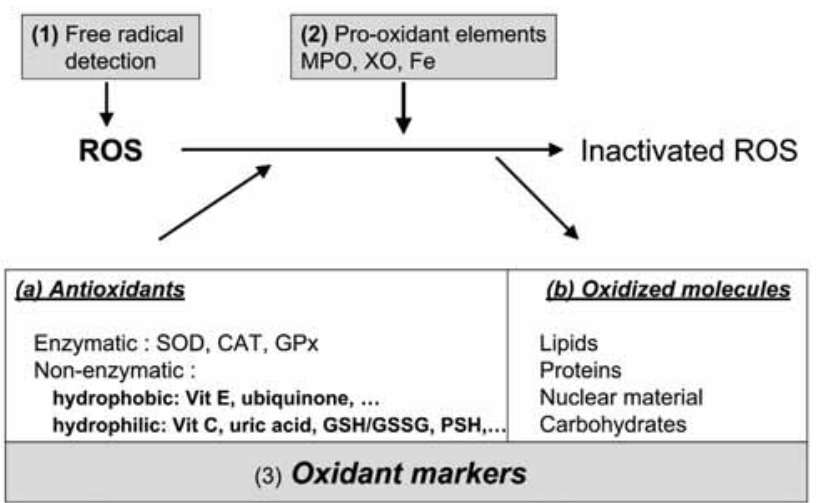

Fig 3 Principal methods of assessment of oxidative stress. (1) Free radical detection; (2) detection of pro-oxidant elements: MPO: myeloperoxidase, $\mathrm{XO}$ : xanthine oxidase, Fe: iron; (3) detection of oxidant markers: (a) antioxidants: SOD: superoxide dismutase, CAT: catalase, GPx: glutathione peroxidase, GSH/GSSG: glutathione, PSH: thiol proteins; (b) oxidized molecules.

Darstellung der wichtigsten diagnostischen Methoden bei oxidativem Stress. (1) Erkennung freier Radikale; (2) Erkennung pro-oxidativer Elemente: MPO: Myeloperoxydase, XO: Xanthine-Oxydase, Fe: Eisen; (3) Erkennung oxidativer Marker: (a) Antioxidantien: SOD: Superoxid-Dismutase, CAT: Catalase, GPx: Glutathionperoxidase, GSH/GSSG: Glutathion, PSH: Thiol-Proteine; (b) oxidierte Moleküle. 
(EIPH) (Derksen, 1997). Indeed, ROS might contribute to microvascular damage, favour the release of inflammatory mediators and reduce the generation of nitric oxide, a vasodilator. Weakened pulmonary microvessels and increased vasoconstriction during intense exercise could lead to EIPH, which will itself reinforce lower airway inflammation and induce ROS release (Fig 4). However, to the best of the authors' knowledge, studies demonstrating the implication of oxidative stress in EIPH are not published.

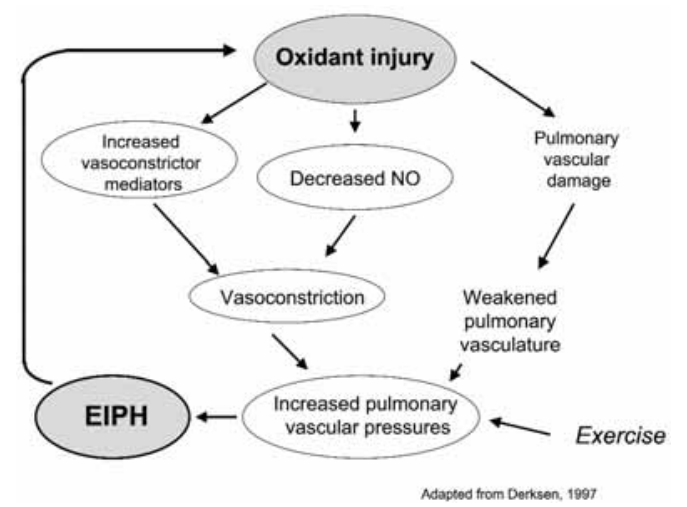

Fig 4 Hypothetical role of oxidative injury in exercise-induced pulmonary haemorrhage (EIPH).

Mögliche Rolle des oxidativem Stress bei belastungs-induziertem Lungenbluten.

Oxidative stress in equine motor neuron disease

Equine motor neuron disease (EMND) is a sporadic neurodegenerative disorder of unknown aetiology, which is believed to be associated with oxidative stress. Indeed, EMNDaffected horses have decreased serum concentrations of vitamin $\mathrm{E}$ and poorly respond to supplementation (Delguste et al., 2002). Furthermore, increased concentrations of copper, which is considered as a pro-oxidant element, have been found in the cerebrospinal fluid of EMND-affected horses (Polack et al., 2000) and clinical improvement of this condition by Vitamin $\mathrm{E}$ and selenium supplementation has been observed (C. Delguste, unpublished data).

\section{Exercise-related oxidative stress}

Exercise is a potent stimulator of ROS production and there is increasing evidence to suggest that non-compensated ROS production may contribute to exercise-induced disturbances in muscle homeostasis as well as fatigue and injury (Sen and Packer, 2000).

In equine medicine, several studies investigating the effect of different types of exercise (Avellini et al., 1995; Mills et al., 1996a; Chiaradia et al., 1998; Balogh et al., 2001; White et al., 2001; Kirschvink et al., 2002c; Marlin et al., 2002) as well as the effect of different thermal heat loads (Mills et al., 1996a; Hargreaves et al., 2002) are published. Despite some discrepancies between study results, which can be explained by different experimental designs, different analytic techniques and the use of different oxidant markers, it can be concluded that exercise is inducing significant alterations of the circulatory oxidant-antioxidant balance in horses. Moreover, it appears that exercise intensity (oxygen consumption or heart rate), duration and atmospheric conditions $\left(\mathrm{T}^{\circ}\right.$, relative humidity) are determining factors for this exercise-induced pro-oxidant burden. One factor that is currently under investigation in horses is the effect of training on the endogenous antioxidant defence system (de Moffarts et al., unpublished data). As it has been shown that training improves the circulatory and tissue antioxidant capacity in laboratory rodents and human athletes (Ji et al., 1998), it appears interesting to determine the type of training schedule allowing to optimally prepare the antioxidant body defence prior an important performance.

Since the role of antioxidant deficiencies in exercise-induced oxidative stress and exercise intolerance has been clearly established in laboratory animals and human athletes, antioxidant supplementation is widely practised in human sports medicine, even if the effectiveness of antioxidant supplements remains to be proven (Clarkson and Thompson 2000; Jenkins 2000). In equine medicine, some scientific studies are presently investigating the effect of specifically adapted antioxidants for horses performing in different disciplines (Williams et al., 2002; B. de Moffarts, personal communication).

\section{Conclusions and future directions}

The present review aimed to give a short overview about the significance of oxidants, antioxidants and oxidative stress as well as about the current research results in equine medicine. Oxidative stress is constantly gaining attention in human medicine and first results in equine medicine suggest that specifically adapted antioxidants might be of interest for the management of some pathological conditions. With regard to exercise, it remains to be proven whether a stable equilibrium between oxidants and antioxidants improves performance, but it probably contributes to improved animal welfare.

\section{Acknowledgements}

The authors would like to thank Martine Leblond for typing the manuscript and C. Delguste and B. de Moffarts for helpful disussions.

\section{Literature}

Art, T., N. Kirschvink, N. Smith and P. Lekeux (1999): Indices of oxidative stress in blood and pulmonary epithelium lining fluid in horses suffering from recurrent airway obstruction. Equine vet. J. 31, 397-401

Avellini, L., M. Silvestrelli and A. Gaiti (1995): Training-induced modifications in some biochemical defences against free radicals in equine erythrocytes. Vet. Res. Commun. 19, 179-184.

Babior, B.M. (2000): Phagocytes and oxidative stress. Am. J. Med. 109, 33-44

Balogh, N., T. Gaal, P.S. Ribiczeyne and A. Petri (2001): Biochemical and antioxidant changes in plasma and erythrocytes of pentathlon horse before and after exercise. Vet. Clin. Pathol. 30, 214-218

Beckman, K.B. and B.N. Ames (1998): The free radical theory of aging matures. Physiol. Rev. 78, 547-581

Cheeseman, K.H. and T.F. Slater (1993a): An introduction to free radical biochemistry. Br. Med. Bull. 49, 481-493

Chiaradia, E., L. Avellini, F. Rueca, A. Spaterna, F. Porciello, M.T. Antonioni and A. Gaiti (1998): Physical exercise, oxidative stress and muscle damage in racehorses. Comp. Biochem. Physiol. B Biochem. Mol. Biol. 1 19, 833-836 
Clarkson, P.M. and H.S. Thompson (2000): Antioxidants: what role do they play in physical activity and health? Am. J. Clin. Nutr., 72 (Suppl. 2), 637S-646S

Cuzzocrea, S., D.P. Riley, A.P. Caputi and D. Salvemini (2001): Antioxidant therapy: a new pharmacological approach in shock, inflammation, and ischemia/reperfusion injury. Pharmacol. Rev. 53, 135-159

Davies, K.J., A.T. Quintanilha, G.A. Brooks and L. Packer (1982): Free radicals and tissue damage produced by exercise. Biochem. Biophys. Res. Commun. 107, 1198-1205

de Zwart, L.L., J.H.N. Meerman, J.N.M. Commandeur and N.P.E. Vermeulen (1999): Biomarkers of free radical damage applications in experimental animals and in humans. Free Radic. Biol. Med. 26, 202-226

Delguste, C., B. de Moffarts, C. Sandersen, M. Debrue, H. Guyot and H. Amory (2002): Serum vitamin E concentrations in a group of horses, with a high incidence of equine motor neuron disease. Pflügers Arch. Eur. J. Physiol., 2002, March, R3

Derksen, F.J. (1997): Oxidant injury and nitric oxide: a role in exercise-induced pulmonary haemorrhage? Vet. J. 153, 119-122

Favier, A.E. (1995): How to demonstrate the occurrence of an oxidative stress in human. In: A.E. Favier, J. Cadet, B. Kalyanaraman, M. Fontecave, J.-L. Pierre (eds.), Analysis of Free Radicals in Biological Systems, Birkhäuser Verlag, Basel, 99-117

Fridovich, I. (1995): Superoxide radical and superoxide dismutases. Annu. Rev. Biochem. 64, 97-112

Hargreaves, B.J., D.S. Kronfeld, J.N. Waldron, M.A. Lopes, L.S. Gay, K.E. Saker, W.L. Cooper, D.J. Sklan and P.A. Harris (2002): Antioxidant status of horses during two $80-\mathrm{km}$ endurance races. J. Nutr. 132 (6 Suppl 2), 1781S-1783S

Hawkins, C.L. and M.J. Davies (2001): Generation and propagation of radical reactions on proteins. Biochim. Biophys. Acta 1504, 196-219

Hensley K., K.A. Robinson, S.P. Gabbita, S. Salsman and R.A. Floyd (2000): Reactive oxygen species, cell signaling, and cell injury. Free Radic. Biol. Med. 28, 1456-1462

Jenkins, R.R. (2000): Exercise and oxidative stress methodology: a critique. Am. J. Clin. Nutr. 72, 670S-674S

Ji, L.L. (1995) : Oxidative stress during exercise : implication of antioxidant nutrients. Free Radic. Biol. Med. 18, 1079-1086

Ji, L.L., C. Leeuwenburgh, S. Leichtweis, M. Gore, R. Fiebig, J. Hollander and J. Bejma (1998): Oxidative stress and aging. Role of exercise and its influences on antioxidant systems. Ann. N Y Acad. Sci. 854, 102-117

Kirschvink, N., N. Smith, L. Fiévez, V. Bougnet, T. Art, G. Degand, D. Marlin, C. Roberts, B. Genicot, P. Lindsey and P. Lekeux (2002a): Effect of chronic airway inflammation and exercise on pulmonary and systemic antioxidant status of healthy and heaves-affected horses. Equine Vet J., in press

Kirschvink N., L. Fiévez, V. Bougnet, T. Art, G. Degand, N. Smith, D. Marlin, C. Roberts, P. Harris and P. Lekeux (2002b): Effect of nutritional antioxidant supplementation on systemic and pulmonary antioxidant status, airway inflammation and lung function in heaves-affected horses. Equine Vet. J., in press

Kirschvink, N., T. Art, B. de Moffarts, N. Smith, D. Marlin, C. Roberts and P. Lekeux (2002c): Relationship between markers of blood oxidant status and physiological variables in healthy and heavesaffected horses after exercise. Equine vet. J., Suppl., in press

Kobayashi T., S. Tsunawaki and H. Seguchi (2001): Evaluation of the process for superoxide production by NADPH oxidase in human neutrophils: evidence for cytoplasmic origin of superoxide. Redox Rep. 6, 27-36

Kostoryz, E.L. and D.M. Yourtee (2001): Oxidative mutagenesis of doxorubicin-Fe(III) complex. Mutat. Res. 490, 131-139

Kowaltowski, A.J. and A.E. Vercesi (1999): Mitochondrial damage induced by conditions of oxidative stress. Free Radic. Biol. Med. 26, 463-471

MacPherson, J.C., S.A.A. Comhair, S.C. Erzurum, D.F. Klein, M.F. Lipscomb, M.S. Kavuru, M.K. Samoszuk and S.L. Hazen (2001): Eosinophils are a major source of nitric oxide-derived oxidants in severe asthma: characterization of pathways available to eosinophils for generating reactive nitrogen species. J. Immunol. 166, 5763-5772.
Marlin, D.J., K. Fenn, N. Smith, C.D. Deaton, C.A. Roberts, P.A. Harris, C. Dunster and F.J. Kelly (2002): Changes in circulatory antioxidant status in horses during prolonged exercise. J. Nutr. 13216 Suppl 2), 1622S-1627S

Matés, J.M. (2000): Effects of antioxidant enzymes in the molecular control of reactive oxygen species toxicology. Toxicology 153, 83104

Maughan, R.J. (1999): Role of micronutrients in sport and physical activity. Br. Med. Bull. 55, 683-690

Mills P.C., N.C. Smith, I. Casas, P. Harris, R.C. Harris and D.J. Marlin (1996a): Effects of exercise intensity and environmental stress on indices of oxidative stress and iron homeostasis during exercise in the horse. Eur. J. Appl. Physiol. Occup. Physiol. 74, 60-66

Mills, P.C., C.A. Roberts and N.C. Smith (1996b): Effects of ozone and airway inflammation on glutathione status and iron homeostasis in the lungs of horses. Am. J. vet. Res. 57, 1359-1363

Nivière, V. and M. Fontecave (1995): Biological sources of reduced oxygen species. In: A.E. Favier, J. Cadet, B. Kalyanaraman, M. Fontecave, J.-L. Pierre (eds.): Analysis of Free Radicals in Biological Systems. Birkhäuser Verlag, Basel, 11-19

Noguchi, N. and E. Niki (1999): Chemistry of active oxygen species and antioxidants. In: A.M. Papas (eds.): Antioxidant Status, Diet, Nutrition, and Health. CRC Press LLC, London

Pincemail, J., J.O. Defraigne and M. Meurice (1997): Les radicaux libres, système cardiovasculaire et pathologies inflammatoires. Medi-Sphere 55, 8-12

Polack, E.W., J.M. King, J.F. Cummings, H.O. Mohammed, M.Birch and T. Cronin (2000): Concentrations of trace minerals in the spinal cord of horses with equine motor neuron disease. Am. J. vet. Res. 61, 609-611

Rahman, I., D. Morrison, K. Donaldson and W. MacNee (1996): Systemic oxidative stress in asthma, COPD, and smokers. Am. J. Respir. Crit. Care Med. 154, 1055-1060

Reilly, C.A. and S.D. Aust (1999): Biological oxidations catalyzed by iron released from ferritin. In: C. Rhodes (eds.): Toxicology of Xenobiotic Free Radicals. Taylor \& Francis, London, 155-190

Sen, C.K. and L. Packer (2000): Thiol homeostasis and supplements in physical exercise. Am. J. Clin. Nutr. 72 (2 Suppl.), 653S-669S

Sies, H. (1991): Oxidative stress: introduction. In: H. Sies (ed.): Oxidative Stress: Oxidants and Antioxidants. Academic Press, London, $\mathrm{xv}$-xxii

Stamler, J.S. and G. Meissner (2001): Physiology of nitric oxide in skeletal muscle. Physiol. Rev. 81, 209-237

Tremblay, S., T. Douki, J. Cadet and J.R. Wagner (1999): 2'-Deoxycytidine glycols, a missing link in the free radical-mediated oxidation of DNA. J. Biol. Chem. 274, 20833-20838

White, A., M. Estrada, K. Walker, P. Wisnia, G. Filgueira, F. Valdes, O. Araneda, C. Behn and R. Martinez (2001): Role of exercise and ascorbate on plasma antioxidant capacity in thoroughbred race horses. Comp. Biochem. Physiol. A Mol. Integr. Physiol. 128, 99 104

Williams, C.A., R.M. Hoffman, D.S. Kronfeld, T.M. Hess, K.E. Saker and P.A. Harris (2002): Lipoic acid as an antioxidant in mature thoroughbred geldings: a preliminary study. J Nutr. 132 (6 Suppl 2), 1628S-1631S

Winrow, V.R., P.G. Winyard, C.J. Morris and D.R. Blake (1993): Free radicals in inflammation: second messengers and mediators of tissue destruction. Br. Med. Bull. 49, 506-522

Young, I.S. and J.V. Woodside (2001): Antioxidants in health and disease. J. Clin. Pathol. 54, 176-186

Nathalie Kirschvink, DVM, PhD

Department for Functional Sciences

Faculty of Veterinary Medicine, University of Liege

Sart Tilman, Bât B42, B-4000 Liège

nathalie.kirschvink@ulg.ac.be 